\title{
Dimensão dos Problemas Éticos Implicados na Educação Médica
}

\section{Dimension of Ethical Problems Implied in Medical Training}

\author{
Carlos Alberto Severo Garcia-Jr. ${ }^{\text {IC }}$ \\ Marta Inês Machado Verdi ${ }^{I I}$
}

\section{PALAVRAS-CHAVE}

- Ética.

- Educação Médica.

- Estudantes de Medicina.

\footnotetext{
I Universidade Federal de Santa Catarina, Araranguá, Santa Catarina, Brasil.

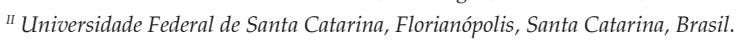




\section{KEY-WORDS}

- Ethics.

- Medical Education.

- Medical Students.

Recebido em: 2/4/19

Aceito em: 24/4/19
ABSTRACT

Medical education is required to continuously adapt its curriculum guidelines according to social demands. Raising the theme of ethical problems in medical education entails using a possible artifice to contribute toward understanding the diverse needs of the Brazilian population. The objective of this study is to analyze the ethical problems experienced by the students and professors of the University of Vale do Itajai (Univali) medical course. This is a qualitative study. The study participants were students from the $1^{\text {st }}$ to $7^{\text {th }}$ semesters of the medical course and the institution's teachers. Data were collected through focus groups with the students and a collective interview with the teachers. The collected data were coded and categorized for content analysis. The students think that tackling ethical problems in medical education equates to the need to learn to deal with themselves and spread debate and study of ethics at the medical school. The teachers believe that ethical problems should be addressed through the following actions: (1) empowering the students to stand up to repressive forces; (2) strengthening collective decision-making practices within institutional spaces; (3) continuing teacher training; (4) giving value to teachers with a foundation based on planning and collective actions and linked to the National Curricular Guidelines of the medical course. The identification of knowledge about the subject reflects the inseparable relationship between the knowledge of teachers and students and the institutionalization of medical education in relation to ethical problems. These are present throughout all the academic periods of the medical course analyzed, although they are not always cited or visible, and are therefore, directly or indirectly, cross curricular disciplines and spaces of practices. The research participants identify the incongruities in the training with discrepancies between theory and practice, from teacher-student relations to the relations between the institution and teacher/student.

\section{INTRODUÇÃO}

As Diretrizes Curriculares Nacionais (DCN) do Curso de Graduação em Medicina apontam a necessidade de uma formação do graduando em Medicina com ofertas de ensino e aprendizagem abrangentes e direcionadas à constituição de sujeitos críticos, reflexivos e éticos ${ }^{1}$. Trata-se, de modo geral, de induzir uma formação com diferentes conteúdos contextualizados, problematizadores e conectados a três grandes áreas da saúde: Atenção, Gestão e Educação. Portanto, ratifica-se a indissociabilidade entre teoria e prática, reforçando o fortalecimento de uma visão integral do homem e a ampliação da capacidade de compreensão do processo saúde-doença e cuidado na sociedade.

Contudo, o ensino médico tradicional, dividido em ciclo básico, clínico e internato, está concentrado na concepção saúde-doença tida pela escola médica e seus docentes ${ }^{2}$. Por isso, a desfragmentação dos saberes e a participação ativa do acadêmico e do docente são peças-chave no processo de integração entre os sujeitos em aprendizagem e as instituições de ensino. Segundo Freire ${ }^{3}$, docência e discência não podem ser separadas, assim como ensinar não pode ser reduzido a transferir. $\mathrm{O}$ autor alerta sobre a permanente necessidade de se reformular para formar, bem como sobre a premissa de que o formador é um sujeito em relação. Ensinar, portanto, exige pesquisa, respeito aos saberes dos educandos, ética, criatividade, reflexão crítica sobre a prática e corporificação das palavras pelo exemplo.

Estudos da realidade da formação ética dos futuros médicos nas escolas de Medicina do Brasil indicam as dificuldades com que os jovens profissionais se deparam quando passam de "aprendizes" para a posição em que têm que responder moral, jurídica e socialmente pela vida de um semelhante ${ }^{4}$. Problemas éticos na formação médica ainda são um vasto campo a ser explorado, embora já existam estudos na área ${ }^{5-9}$.

Do ponto de vista conceitual, como afirma Guedert ${ }^{10}$, "problema" ético extrapola a noção de "dilema" ético, pois neste as situações apontam apenas duas possibilidades inconciliáveis, enquanto naquele envolvem questões abertas, no qual podem ser construídas soluções prudentes, embora nem sempre corretas. Na concepção de Diego Gracia ${ }^{11}$, médico e filósofo espanhol, os problemas éticos surgem pela necessidade da escolha de uma ação entre distintas possibilidades. Para o autor, o que se nota com frequência é uma tentativa 
de transformar os "problemas" em "dilemas" para simplificar as análises em duas alternativas, geralmente extremas e com consequências trágicas. Além disso, de acordo com o autor, um problema não é um conflito, pois este consiste no choque de duas ou mais situações, enquanto o problema se apresenta como uma necessidade de eleger uma ação.

Nesse sentido, buscamos questionar quais são e de que forma são vivenciados, no processo de formação dos estudantes de Medicina, os problemas éticos que emergem na educação médica. Tem-se como objetivo, analisar, sob a perspectiva dos estudantes e dos docentes de Medicina, os problemas éticos que envolvem o ensino e a assistência no acompanhamento de atividades de atenção e educação em saúde. Especificamente, identificar os principais problemas éticos vivenciados pelos participantes do estudo, identificar fatores que interferem na constituição de problemas éticos, explorar associações entre problemas éticos e formação acadêmica, e analisar as estratégias, dentro da formação acadêmica, de enfrentamento dos problemas éticos.

\section{MÉTODO}

Trata-se de um estudo qualitativo exploratório com abordagem mista. $\mathrm{O}$ método qualitativo permite desvelar processos sociais quando o estudo se insere no universo dos significados, motivos, aspirações, atitudes, crenças e valores, que são elementos de difícil mensuração com médias, gráficos e estatísticas ${ }^{12}$. A utilização da abordagem descritiva tem como finalidade estudar as características de um grupo e sua distribuição, pesquisar opiniões e descobrir associações entre variáveis, entre outros.

A pesquisa foi desenvolvida junto ao curso de Medicina da Universidade do Vale do Itajaí (Univali), Santa Catarina, Brasil, no ano de 2018. O projeto pedagógico do curso de Medicina da Univali, na sua versão de 2015, caracteriza o curso de regime integral, com admissão por processo seletivo vestibular semestral, período mínimo de conclusão de 12 semestres, divididos entre os ciclos básicos e pré-clínicos (oito semestres) e o internato médico (quatro semestres). Apresenta carga horária total de 8.295 horas, sendo 4.500 horas em estágio obrigatório (Internato). Possui 152 docentes e 451 discentes.

Embora o projeto pedagógico registre a proposta de um currículo integrado, deve-se destacar que o curso tem maior enfoque clínico, apresentando a seguinte distribuição: disciplinas de humanidades médicas respondem por 210 horas (entre o primeiro e o sétimo período), 90 horas de disciplina de metodologia científica/trabalho de iniciação científica, 105 horas para a disciplina de saúde mental, 1.080 horas para as disciplinas de base biológica, 420 horas para Saúde Coletiva/
Atenção Básica (divididas entre teoria e práticas nas unidades básicas de saúde até o sétimo período e um estágio obrigatório no oitavo período no internato médico), 1.290 horas em disciplinas clínicas e 4.050 horas em estágio curricular (internato médico em Pediatria, Ginecologia-Obstetrícia, Saúde Mental, Clínica Médica, Clínica Cirúrgica e medicina de família e comunidade). Em termos da estrutura do currículo do curso, são 12 semestres, em que os oito primeiros se referem à formação teórico-prática, enquanto os quatro últimos são destinados ao internato médico, ou seja, aos estágios curriculares obrigatórios $^{13}$.

Os participantes deste estudo foram acadêmicos do primeiro ao sétimo período do curso de Medicina e docentes do mesmo curso, em atividade durante o ano de 2018. O total de participantes foi de 34 acadêmicos, sendo 20 mulheres e 14 homens, e quatro professores, sendo um homem e três mulheres, somando 38 participantes. Os critérios de inclusão dos discentes foram: (1) matrícula entre o primeiro e o sétimo período do curso de Medicina; (2) maiores de 18 anos. Para os docentes foram considerados: (1) vínculo de mais de dois anos em atividades didático-pedagógicas; (2) em atividade durante o ano de 2018. Foram excluídos do estudo os discentes em período de internato e docentes com carga horária semanal igual ou inferior a 30 horas no curso de Medicina.

Os instrumentos de coleta de dados foram grupos focais realizados com os discentes e entrevista coletiva com os docentes. Nos grupos e entrevista coletiva foram utilizados roteiros semiestruturados com o intuito de criar pontos em comum para promover a reflexão e a troca de experiências relacionadas aos problemas éticos na formação médica. Os dados coletados foram analisados por meio da perspectiva da abordagem social de Minayo, na qual se descreve e interpreta a fala dos sujeitos para formular categorias de análise ${ }^{12}$. Foram utilizados depoimentos ilustrativos.

O presente estudo foi aprovado pelo Comitê de Ética em Pesquisa da Univali, número CAAE 87856118.3.0000.0120, conforme o parecer 2.711.376, disponível em 13/06/2018. Não contou com fonte de financiamento e não possui conflito de interesses.

\section{RESULTADOS}

Os resultados desta pesquisa se estruturam com base nos testemunhos de discentes e docentes com direta inserção no curso de Medicina e que estão intimamente relacionados à instalação do novo projeto pedagógico recomendado pelas DCN em 2014, porém sob influência indireta de outros regimes de ensino tão históricos quanto a própria construção da medicina no Ocidente. A análise dos resultados expressa alguns frag- 
mentos dos grupos focais e da entrevista coletiva. Com uma sequência de "cenas-imagens" problematiza-se a formação ética em Medicina no âmbito das práticas do cuidado em saúde. Foram criados alguns pontos "comuns" e "emergentes" para integrar categorias temáticas que abarcassem valores, explicações, entendimentos e generalizações das falas. Não se trata de reduções, pelo contrário, foram enfatizados trechos que pudessem sintetizar ideias significativas. De maneira geral, apresenta-se um conjunto de concepções e características distribuídas em três eixos analíticos: discentes, docentes e disciplinas. Especificamente, fundamentam-se duas grandes categorias temáticas transversais que versam sobre a relação entre docente e discente, e a relação entre instituição e docente/discente.

Os discentes ponderam suas vivências no curso de Medicina por meio de diferentes significações, criticidades, problematizações, historicidade, continuidades e rupturas. Contudo, essas marcas se encontram consolidadas numa estrutura curricular obrigatória e em estruturas curriculares invisíveis, ditas "ocultas". Ao longo dos grupos focais, as expressões da invisibilidade do sofrimento inerente à formação médica, por exemplo, apareceram como no desabafo seguinte:

Antes de começar este semestre, eu estava com muito medo. Comentei com alguns veteranos. Porque uma semana antes de chegar aqui [universidade] eu chorei todos os dias à noite com medo do semestre. Será que isso é normal? Será que isso é um problema meu? Será que isso é uma falta de comprometimento da minha parte? (discente A)

Os discentes identificam as "contradições" que habitam o ensino médico. Ao revelarem o sofrimento e as expectativas diante da construção do conhecimento, os discentes se confrontam com a assombração do fracasso, da incompetência e da inaptidão. Ao mesmo tempo, problematizam os mecanismos psicológicos defensivos emergentes da própria formação da identidade médica. A confirmação desta inferência, em parte, deu-se na fala de um discente durante um grupo focal:

Será que a questão de o médico ser arrogante não tem relação com o medo dos sentimentos que ele tem? Porque ninguém nos ensinou a lidar com esses sentimentos e a gente não sabe como fazer isso. Na minha família não tem nenhum médico. Ninguém que pode me dizer: "é assim!". "Tu está indo no caminho certo!" (discente A)

Em outro exemplo, um acadêmico relata a decisão de se afastar de uma pesquisa, pois o professor orientador solicitou a inclusão do nome de outra pessoa na produção do artigo sem a participação do sujeito no trabalho. Percebe-se o incômodo do estudante decorrente da percepção de assédio na extrapolação dos limites da idoneidade e, ao mesmo tempo, o evidente abuso de autoridade na relação.

Em outra situação, uma discente manifesta insatisfação com a incoerência entre as normas e as repetições no processo de aprendizagem, que se revela mais próximo da inculcação do que do processo ativo de ação-reflexão-ação, conforme se pode observar:

Como acadêmica, vejo como desestimulante a forma como os professores atuam mecanicamente nos processos reflexivos; seja por priorizarem conhecimentos técnicos ou conhecimentos protocolados em seus estudos e prática na área médica. (discente B)

Os futuros médicos se deparam com uma discursividade de espelhamento, alicerçados em conflitos de valores morais de docentes. O discurso da relevância da ética médica se contrapõe à prática docente divergente, promovendo uma desarmonia com suas condutas e decisões, conforme o seguinte depoimento:

Os mesmos professores que relatam a importância da ética médica, preocupação com os pacientes, sigilo, etc. são os mesmos que, em determinadas situações, como nas avaliações, comentam de forma maldosa o que se deve "esperar" da prova. (discente B)

Os discentes falam de vivências e violências - muitas vezes, banalizadas - produzidas em cenários de práticas e nas disciplinas em sala de aula. Ao mesmo tempo, os docentes também reconhecem problemas éticos na "conduta e comportamento" do próprio professor no atendimento aos pacientes com a presença ou a participação de alunos. Um dos docentes pontua:

Mesmo com a dita valorização da boa relação médico-paciente, na prática ocorre o contrário do desejado. Exemplos disso podem ser percebidos nas disciplinas de Clínica Médica e Clínica Cirúrgica. Notam-se professores com atitudes "grosseiras" e "rudes", tanto com os pacientes quanto com os alunos. (docente A)

Assim, percebe-se que os docentes denunciam a desarticulação teoria/prática, discurso/gesto, isto é, aquilo que é ensinado (arcabouço teórico) em sala de aula apresenta certa 
dissociação da prática. Um dado que merece destaque são os "mecanismos de avaliação dos processos de ensino-aprendizagem", como um dos docentes destacou:

As avaliações são pelo "susto" e "medo". Assim, os alunos não estudam porque querem ou gostam, mas porque têm medo, provocado pelos professores. (docente B)

Por outro lado, alguns docentes afirmam que, ao se propor a construção de outra lógica avaliativa, processual e sem o uso do "mecanismo" do medo, o efeito, muitas vezes, é que os alunos deixam de estudar determinada disciplina para estudar outra em função do risco de reprovação. Por fim, prevalece o sentimento do medo, pois os alunos acabam estudando aquela(s) disciplina(s) de que têm "mais" medo.

Os docentes revelam preocupação com as práticas de ensino induzidas por eles próprios e com a maneira como os discentes, sobretudo dos primeiros períodos, se relacionam com disciplinas básicas vinculadas às estruturas anatômicas e fisiológicas. Com base em relatos em sala de aula, identificam vivências que resultam em adoecimento e pânico diante das avaliações. Ao mesmo tempo, a competitividade entre pares resulta no distanciamento de alguns vínculos afetivos e na presença de zombarias depreciativas.

Além disso, conforme os participantes, a influência da dimensão subjetiva se expressa como um elemento indecifrável na avaliação do processo de ensino-aprendizagem, sobretudo no internato. Esta situação se revela, por vezes, pelo uso de critérios avaliativos com uma "padronização" de notas de acordo com as características de cada grupo, além de provocar discrepância entre atitudes e competências dos alunos. Os participantes reconhecem que raras vezes os alunos questionam diretamente os professores sobre as notas recebidas e seus critérios, prevalecendo outro tipo de medo, o da punição ou futuras punições. Os alunos comentam entre seus pares ou com professores "mais abertos", porém sem romper a lógica de obediência e opressão.

Os docentes revelam "práticas de exclusão" dos alunos na tomada de decisões vinculadas ao planejamento e execução de ações no ensino médico, isto é, os professores adotam contratos e normas sem a participação dos alunos. No trecho a seguir pode-se identificar essa característica:

Um grande problema ético é a gente (docente), às vezes sem querer - inclusive eu já fiz isso-, excluir os alunos das decisões. Tipo assim: os alunos passam as coisas, a gente resolve o que deve ser feito e não inclui eles. Não puxa eles juntos. $E$, às vezes, são alunos do décimo segundo período, alunos que estão se formando. E isso deixa eles muito inseguros. (docente C)

A ausência de pactuações compartilhadas e dialogadas pode desencadear um processo de afastamento da relação docente-discente. Além da exclusão, os docentes apontam que os discentes também sinalizam a "falta de compromisso" de alguns professores:

Eu não consigo questionar por que, por exemplo, dar sete para todos os alunos. Imagina os alunos. Por que o sete para todos? Eu não consigo! O que barra questionar os colegas (docentes) é a resposta que eu sei que vou ouvir, entendeu? (docente C)

Os docentes reconhecem como ações de enfrentamento dos problemas éticos os seguintes itens: (1) empoderamento dos alunos: conforme se percebe na fala de um docente, "se os alunos soubessem quem eles são e o que eles podem...", isto é, a concentração de poder dos discentes para enfrentar as forças repressivas; (2) fortalecimento de práticas de tomadas de decisão coletivas no âmbito dos espaços institucionais, como, por exemplo, nas diferentes instâncias colegiadas; (3) formação continuada dos professores; (4) valorização dos professores com uma formação alicerçada no planejamento e ações de cunho coletivo, como saúde coletiva, refletindo-se em práticas docentes diferenciadas, demarcando a diferença entre o intelectual teórico e "orgânico".

Para os discentes, enfrentar os problemas éticos da formação médica remete à necessidade de aprender a lidar consigo mesmo e difundir o debate e o estudo da ética no curso de Medicina. No depoimento seguinte, pode-se identificar na formação médica a desarticulação entre o reconhecimento de uma doença e a capacidade de elaborar um plano de cuidado com o sujeito adoecido, aludindo a um efeito supostamente prometido para a tomada de decisões necessárias diante de problemas éticos.

\footnotetext{
A nossa formação foge dos dilemas e enfrentamentos éticos. A faculdade não te prepara para isso. Até nas últimas aulas que a gente teve sobre neoplasia - que é uma coisa que chama atenção -, você sabe tudo, a patologia, o tratamento, tudo! Tá, e como cuida do paciente? O ambiente em que a gente vive não quer que a gente se prepare, quer que a gente aprenda (ou não). Eu não sei se vou estar preparada quando uma situação dessas acontecer. (discente C)
}

Desse modo, nota-se uma quebra de continuidade entre as disciplinas curriculares e a essência da ação técnica, ética 
e política nas práticas de cuidado em saúde. Por conseguinte, disciplinas "transversais", como "Humanidades Médicas" e "Saúde Coletiva", são identificadas pelos discentes como disciplinas abstratas, recreativas, repetitivas, ideológicas e, muitas vezes, sem foco. Alguns discentes afirmam que esses fatores tornam as aulas cansativas e com debates exaustivos e que "não chegam a lugar nenhum". Além disso, os discentes consideram que a disciplina de Humanidades Médicas não tem "prática" e é incapaz de oferecer respostas (saber) para solucionar determinados problemas; portanto, tem pouca importância. Em um dos grupos focais uma discente referiu o sentimento da seguinte maneira:

A gente foca muito em cuidar do outro, mas a maneira como a gente vai aprender a lidar com o outro é algo que deveria ser mais trabalhado, nessa cadeira (Humanidades Médicas) principalmente. E foi o que eu achei que iria ser desde a primeira aula magna. A gente não é preparada para lidar com o outro. Eu achei que a Humanidades Médicas iria ajudar a gente com isso. É uma frustração que eu tenho! (discente D)

Para outros, a disciplina de Humanidades Médicas subsidia algumas reflexões importantes na medicina e para o futuro dos acadêmicos, e, às vezes, também é vista como uma "válvula de escape" das dificuldades enfrentadas no curso. A fala a seguir dá algumas pistas sobre a ilusão quanto a respostas "ideais":

Ninguém vai conseguir te preparar $100 \%$. Cobrar uma coisa dessas é utopia. Mas acho que é mostrar caminhos... sei lá! Trilhar caminhos, que é o que a gente tem aqui! E a gente vê o que é melhor para a gente seguir. Ninguém vai estar preparado para falar com uma mulher cujo marido morreu e a filha está doente. Seria bom se a gente tivesse um manual. Se existisse um manual utópico, eu sei (risos). Olha: "nesses assuntos você vai falar assim!". E vai dar certo, 100\%! Só que a gente sabe que não é bem assim. A gente precisa de noções maiores. (discente $\mathrm{E})$

Em relação à disciplina, os docentes constatam no ensino médico uma moderação das relações entre "medo" e "mode10 ", seja em determinadas disciplinas e/ou professores em que o aluno não se sente confortável para fazer perguntas e questionar o andamento das aulas, seja pela idealização representativa do padrão a ser alcançado. Dois exemplos antagônicos e complementares a respeito destes dois tipos de relação do discente com a medicina: na disciplina Clínica Cirúrgica, um discente diz ter "vergonha de ter dúvida", e outro, do primeiro período, afirma que espera se tornar um cirurgião médico.

\section{DISCUSSÃO}

O estudo sobre a Demografia Médica no Brasil ${ }^{14}$, edição de 2018, apresenta dados e informações estatísticas por meio de tabelas, gráficos e descrições de aspectos demográficos da profissão médica no País. Entre os elementos expostos, convém destacar a integração do tema da "ética" nesse relatório de pesquisa.

O perfil e a percepção dos recém-graduados em Medicina no Brasil sobre a conduta ética vivenciada no curso de graduação revelam cinco grandes categorias de "inadequações": (1) nas relações com pacientes em ambulatório, enfermaria, etc.; (2) nas relações do serviço ou profissionais de saúde com familiares dos pacientes; (3) nas relações do serviço ou profissionais de saúde com a comunidade e o público em geral; (4) nas relações de médicos com colegas, equipe e corpo administrativo; (5) nas decisões em sala de aula. A maioria dos participantes $(85,5 \%, 4.601)$ manifestou ter vivenciado ou assistido no curso a alguma conduta ética que julgou inadequada, e a categoria mais assinalada foi a de relações com pacientes ${ }^{14}$.

Cabe considerar que a expressão "conduta ética" pode ter distintas interpretações, porém, ainda assim, o número de recém-formados em Medicina que percebeu algum tipo de inadequação sobre aspectos éticos é elevado. Em 2018, o Conselho Federal de Medicina (CFM), em conjunto com entidades estudantis vinculadas ao ensino, publicou o Código de Ética do estudante de Medicina com o objetivo de oferecer fundamentos elementares à formação dos estudantes ${ }^{15}$. Trata-se de um documento que ressalta princípios morais e éticos a serem adotados pelo sistema de ensino médico do País. Contudo, mesmo que as DCN e o Conselho profissional valorizem e reforcem a importância e a necessidade do aprofundamento e da qualificação dos estudantes, docentes e profissionais médicos, o contraste com as vivências de problemas éticos demonstra um descompasso persistente na educação médica.

Uma formação problematizadora, crítica e relacionada à integralidade do cuidado em saúde ainda manifesta desafios a serem superados na educação médica. Entre eles: (1) a fragmentação do cuidado, alicerçado no modelo flexneriano ${ }^{16}$; (2) os interesses de mercado, com a valorização das especialidades médicas ${ }^{17}$; (3) as relações de poder e produção de saber nas organizações e grupos de segmentos dominantes ${ }^{18}$; (4) a pedagogia universitária oculta nas organizações de ensino e instituições de educação ${ }^{19}$.

A curricularização da ética, como chamamos, não é em si garantia de problematização de um "outro" agir médico. A estratégia de alicerçar a ética em alguns planos de ensino, por exemplo, ainda permanece afastada do ambiente de intersecção entre discentes e docentes na abordagem de temas transversais no currículo. $\mathrm{O}$ reconhecimento da importância 
dos temas de bioética e humanização da assistência, por exemplo, não é suficiente para promover a transformação no perfil dos profissionais formados ${ }^{20}$. Mesmo as estratégias pautadas em atitudes "humanísticas" acabam sendo deixadas de lado, e, consequentemente, a compreensão e a discussão da condição humana ficam à parte ${ }^{21}$. No entanto, a dimensão ética na formação médica comprova um processo de fortalecimento, visibilidade e qualificação, a exemplo de algumas experiências de escolas médicas no Brasil que reforçam a relevância das Humanidades Médicas no currículo e a valorização de debates com ênfase no cuidado das relações desde o início da graduação $22,23,24$.

Nesse sentido, consideramos que os obstáculos da "ética" da práxis estão na dobra das organizações e dos sujeitos-agentes, isto é, na maleabilidade e no inexplícito eixo de alguns objetos de discussão da ética. Ao mesmo tempo, o próprio currículo pode incluir ou desconsiderar requerimentos e demandas, afastando ou aproximando os discentes do desejado perfil "generalista", induzir a flexibilidade das forças reativas ou embrutecer com a rigidez do disciplinamento. Um exemplo disso pode ser identificado com base na existência ou não de espaços formais e informais para momentos de "pausas" e reflexões sobre os problemas éticos na educação médica. Outro exemplo ilustrativo pode ser identificado com o conhecido ditado popular, também presente nas falas dos participantes, "faça o que eu digo, não faça o que eu faço!", sintetizando o que os docentes e discentes identificam como um ponto comum à práxis ética na formação médica. A representação de uma ideia desconexa entre teoria ("o que digo") e prática ("o que faço") reforça um modelo de pensar e agir conflitante e avesso. "Tem professor que é médico, mas não é todo médico que é professor!" (discente E).

Essa concepção pode estar interligada à postura do professor de medicina que se apresenta com o discurso do médico e não do docente ${ }^{2}$. Nas escolas médicas, o regime de docência com dedicação exclusiva é pouco comum, e o desejo de êxito financeiro induz os professores de medicina a optarem por atividades mais lucrativas e, consequentemente, a terem baixo compromisso com as questões pedagógicas, pouco interesse por discussões e soluções relativas ao ensino médico e resistência às mudanças ${ }^{2}$. É comum, inclusive em concursos públicos, identificarmos como requisitos para o provimento do cargo de docente a baixa exigência de titulação em comparação a outras áreas de conhecimento, considerando, por exemplo, apenas como condições mínimas o título de graduação em Medicina e título de residência em alguma área específica.

A transmissão de um sistema de prêmios e punições usado direta ou indiretamente nas instituições de ensino permite uma formatação e a constituição de uma lógica de significação. Ensinar também pode ser obedecer. Os "calouros" e os "experientes", por exemplo, acostumados a sofrer pressões resultantes das correntes internas conservadoras das forças dos poderes, têm que enfrentar e suportar as limitações impostas pela organização de ensino e seus sujeitos-agentes. Esse sistema de transmissão fomenta um processo de produção de subjetivação. A produção de subjetivação é contingente aos momentos, conjunturas e lugares, constituindo sujeitos singulares nas bordas de cada ato, processo ou resultado de algum acontecimento (acaso) que se caracteriza por ser aleatório, imprevisível e incontrolável ${ }^{25}$.

O processo de (de)formação não é sustentado numa forma universal e invariável de constituição, conforme as próprias DCN, justamente para fomentar transformações e alterações de sentidos; do mesmo modo, os processos de produção de subjetividade na formação médica também são únicos. Portanto, não se trata de variar conteúdos, representações e modalidades de configuração que inevitavelmente resultarão em mudanças para a reprodução de sujeitos idênticos ou similares. As marcas das diferenças e todo o potencial de invenção de discentes e docentes são inseparáveis para submeter a uma permanente problematização da realidade e dos problemas éticos na formação médica.

Contudo, ao longo do percurso formativo, os enfrentamentos dos problemas éticos na formação médica perpassam um conjunto de características e condições que se encontram em determinados momentos e circunstâncias do curso de graduação. A esse conjunto de enfrentamento dos problemas éticos na formação médica denominamos "posições".

A primeira posição é a da "submissão". O estranhamento das relações de uma fratria oprimida. O estado servil. A liberdade desfrutada do "chefe" opressor. Deve-se considerar a rapidez com que essa circunstancialidade se instaura, ocorrendo já no primeiro período do curso, com as primeiras manifestações de avaliações acadêmicas. De tal modo, instaura-se um estado de produção de semelhanças ou analogias entre os sujeitos, com o efeito de uma normatização do comportamento coletivo, ocasionando sistemas de competição e rivalidade, além de um processo de resignação ao ensino médico.

A segunda posição é a do "colapso do estado de submissão". O colapso do estado de submissão dos discentes pode ser equiparado à condição de um sofrimento moral. Isto é, um desequilíbrio psicológico ocasionado por sentimentos de dor e angústia que acontecem quando o sujeito sabe qual a escolha moralmente correta a seguir, porém, em virtude das barreiras institucionais ou conflitos interpessoais, é levado a realizar ações que julga moralmente incorretas ${ }^{26}$. Por meio da 
exposição e vivência com a comunidade acadêmica médica, se estabelecem as afirmações da identidade e as enunciações da diferença traduzidas nas produções simbólicas e discursivas do curso.

A terceira posição é a da "reprodução ou ruptura" de valores. A repetição de enunciados, atos e palavras torna-se o modo de operar, uma retórica e uma duplicação do que é visto. Se, por um lado, os professores se sentem "obrigados" a fazer o que lhes foi ensinado, por outro lado, os alunos utilizam a lógica do domínio/obediência sobre os indivíduos (colegas) que detêm "menos" saber e poder. Essa lógica hierarquizante na formação médica propaga a reprodução de sentidos e valores, crenças e comportamentos "naturalizados" com a profissão médica ou, por outro lado, uma experiência de ruptura da herança e ordenamento dos valores simbólicos e discursivos constitutivos de um simulacro de verdades e virtudes da identidade médica.

Deve-se considerar que essa "categorização" das posições de enfrentamento não é algo fechado, mas um recorte para facilitar a compreensão do objeto com o ensino médico. Não se trata de definir um tempo cronológico determinante para essas posições, pois a variabilidade das experiências deve considerar a singularidade de cada contexto e momento dos sujeitos envolvidos, independentemente do período em que o discente se encontre, por exemplo.

Determinados indícios dessas posições de enfrentamento se configuram com alguns "sinais" e "sintomas". Silêncios, medos, ansiedades, entre outros, carregados de não ditos. Esses sinais e sintomas, de alguma forma, estão sincronizados com a supervalorização das tecnologias duras, com o "rebaixamento" da anamnese e do exame físico e com o distanciamento e as fronteiras que compõem as relações entre discentes e docentes e as relações entre discente/docente e instituição.

$\mathrm{O}$ silêncio assume uma forma de omissão. $\mathrm{O}$ medo expressa um sentimento de impotência. A ansiedade como manifestação do mal-estar diante da agonia e do estado de pavor produzido com a conjectura das condições impostas sobre as avaliações e as supostas exigências das competências necessárias ao progresso no curso. Assim, ligado com esses sinais e sintomas, orbita um conjunto de defesas (negação, idealização, dissociação e projeção) para a garantia da manutenção e continuidade dos elementos institucionais e regulatórios do rito de formação médica.

Desse modo, a produção do processo de subjetivação na formação médica é afetada pela permanente e permeável relação que se estabelece entre discente-docente, docente-docente, docente-discente-paciente. Contudo, a subjetividade é vista como uma anomalia - aquilo que não é previsto - na práti- ca médica, produzindo um fracasso na resolução de enigmas e da objetividade das doenças ${ }^{27}$. Transpondo essa noção de "subjetividade como anomalia" para a formação ética dos estudantes de Medicina, esbarramos no outro "lado" da racionalidade médica, na qual a discussão e a análise de um problema ético podem ser um dispositivo disruptivo e interpor uma outra maneira de produzir um sujeito conectado e reorientado por um aprendizado centrado nas relações humanas. Nos últimos anos, temos visto algumas propostas metodológicas e iniciativas teóricas para aproximar o profissional médico dos pacientes, como o Método Clínico Centrado na Pessoa ${ }^{28}$, o Cuidado Centrado na Relação ${ }^{29}$, a Medicina Narrativa ${ }^{30}$, o que nos faz pensar que a necessidade de reconexão e vínculo entre médico e paciente revela a demanda de qualificação da formação médica.

\section{CONCLUSÕES}

A identificação do conhecimento acerca da temática reflete a inseparável relação entre os saberes dos docentes e discentes e a institucionalização do ensino médico no que diz respeito a problemas éticos. Considera-se que o estudo dos problemas éticos na formação médica possibilita a problematização do projeto político-pedagógico da graduação e a construção de uma perspectiva crítica sobre o sistema de educação do ensino superior focado no ensino médico.

Os resultados desta pesquisa não podem ser generalizados, pois se trata de uma realidade circunscrita e restrita. Por isso, considera-se que este estudo poderá subsidiar o desenvolvimento de outros projetos de pesquisa que abordem a temática.

De maneira geral, considera-se que os problemas éticos estão presentes em todos os períodos do curso de Medicina analisados, ainda que nem sempre ditos ou visíveis, e, portanto, transversais às disciplinas curriculares e aos espaços de práticas, direta ou indiretamente. Os participantes da pesquisa apontam as incongruências existentes na formação, com discrepâncias entre a teoria e a prática, desde as relações entre docente e discente até as relações entre instituição e docente/discente.

A ampliação do grau de comunicação e a participação da comunidade acadêmica do curso de Medicina - rodas de conversa, fóruns, ligas acadêmicas, seminários, grupos de trabalho focados em áreas de interesse ou mesmo com aplicativos de reflexões permanentes - poderiam induzir outras formas de inclusão na construção de escolhas de ações diante dos problemas éticos emergentes. Ampliar o grau de comunicação e participação não é por si só a "solução" para os problemas éticos, mas a constituição de uma comunidade acadêmica aberta à discussão sobre os problemas éticos e com capacidade crítica pode ser um passo importante para a formação. 


\section{REFERÊNCIAS}

1. Brasil. Ministério da Educação. Resolução nº 3, de 2014. Institui Diretrizes Curriculares Nacionais do Curso de Graduação em Medicina e dá outras providências. Diário Oficial da União, DF, 23 jun. 2014. Seção 1, p. 8-11.

2. Cutolo LRA. Estilo de pensamento em educação médica um estudo do Currículo do curso de graduação em Medicina da UFSC. Florianópolis; 2001. Tese [Doutorado] - Universidade Federal de Santa Catarina.

3. Freire P. Pedagogia da Autonomia: saberes necessários à prática educativa. 34. ed. São Paulo: Editora Paz e Terra, 1996.

4. Rego S. A formação ética dos médicos: saindo da adolescência com a vida (dos outros) nas mãos. Rio de Janeiro: Fiocruz; 2003.

5. Taquette SR, Rego S, Schramm FR, Soares LL, Carvalho SV. Situações eticamente conflituosas vivenciadas por estudantes de medicina. Rev. assoc med bras. 2005; Jan-Feb; 51(1):23-8.

6. Almeida AM, Bitencourt AGV, Neves NMBC, Neves FBCS, Lordelo MR, Lemos KM, Nuñez GR, Barbetta MC, Athanazio RA, Nery-Filho A. Conhecimento e Interesse em Ética Médica e Bioética na Graduação Médica. Rev. assoc med bras. 2008; 32(4):437-444.

7. Barbosa MM, Guedert JM, Grosseman S. Problemas éticos relatados por internos com ênfase na saúde da criança. Rev. braseduc med. 2013; 37(1): 21-31.

8. Godoy MF, Ferreira HRA, Pria OAFD. Avaliação do Conhecimento da Ética Médica dos Graduandos de Medicina. Ver. braseduc med. 2014; 38(1): 31-37.

9. Menezes MM, Maia LC, Rocha C, Sampaio CA, Costa SM. Conflitos Éticos Vivenciados por Estudantes de Medicina. Rev. braseduc med. 2017; 41(2): 327-335.

10. Guedert JM. Vivência de problemas éticos em pediatria e sua interface com a educação médica. Florianópolis; 2012. Tese [Doutorado] - Universidade Federal de Santa Catarina.

11. Gracia D. La deliberación como método de la bioética. In: Porto D, Schlemper B, Matins GZ, Hellmann F, orgs. Bioética: saúde, pesquisa, educação. Brasília: CFM/SBB; 2014. p.223-59.

12. Minayo MCS. O desafio do conhecimento. 14. ed. São Paulo: Hucitec, 2014

13. Univali. Projeto Pedagógico do curso de Medicina da UNIVALI. Centro de Ciências da Saúde. Itajaí, 2015.

14. Scheffer M. et al. Demografia Médica no Brasil 2018. São Paulo, SP: FMUSP, CFM, Cremesp, 2018.

15. Conselho Federal de Medicina. Código de ética médica do estudante de medicina. Brasília, DF: CFM, 2018.
16. Pagliosa FL, Ros MA. O Relatório Flexner: Para o Bem e Para o Mal. Rev. braseduc med. 2008; 32(4): 492-499.

17. Luz MT. As instituições médicas do Brasil. 2. ed. Porto Alegre: Rede UNIDA, 2014.

18. Feuerwerker LCM. Além do discurso de mudança na Educação Médica: processos e resultados. São Paulo; HUCITEC, 2002.

19. Vasconcelos EM. Formar profissionais de saúde capazes de cuidar do florescer da vida. In: Vasconcelos EM, Frota LH, Simon E, orgs. Perplexidade na universidade: vivências nos cursos de saúde. São Paulo: HUCITEC, 2006. p. 265-308.

20. Rego $S$ et al. Bioética e Humanização como Temas Transversais na Formação Médica. R Rev. braseduc med. 2008; 32(4): 482-491.

21. Andrade SC, Deus JÁ, Barbosa ECH, Trindade EMV. Avaliação do desenvolvimento de atitudes humanísticas na Graduação Médica. Rev. braseduc med. 2011; 35(4): 517525.

22. Rios IC. Humanidades médicas como campo de conhecimento em Medicina. Rev. braseduc med. 2016; 40(1): 21-29.

23. Ayres JRCM, Rios IC, Schraiber LB, Couto MT, Mota A, Lopes-Junior A, Nasser MA, Suzuki CR. Humanidades como disciplina da graduação em Medicina. Rev. braseduc med. 2013; 37(3): 455-463.

24. Amore Filho ED, Dias RB, Toledo Jr ACC. Ações para a Retomada do Ensino da Humanização nas Escolas de Medicina. Rev. braseduc med. 2018; 42(4): 14-28.

25. Baremblitt G. Compêndio de análise institucional e outras correntes: teoria e prática. 5. ed. Belo Horizonte: Instituto Felix Guattari, 2002.

26. Barth PO, Drago LC, Barlem ELD, Ramos FRS. Sofrimento Moral e a interface com a enfermagem: uma breve revisão sobre o tema. In: Anais do 17º Seminário Nacional de Pesquisa em Enfermagem; 2013 jun 03-05; Natal, Brasil. Rio Grande do Norte: Associação Brasileira de Enfermagem; 2013. p.2484-2486.

27. Guedes CR, Nogueira MI, Camargo Jr KR. A subjetividade como anomalia: contribuições epistemológicas para a crítica do modelo biomédico. Ciênc. saúde coletiva. 2006; 11(4): 1093-1103.

28. Stewart M, Brown JB, Weston WW, McWhinney IR, Freeman TR, McWillian CL. A medicina centrada na pessoa: transformando o método clínico. 2. ed. Porto Alegre: Artmed, 2010.

29. Suchman AL. A New Theoretical Foundation for Relationship-centered Care: Complex Responsive Processes of Relating. J GemIntern Med. 2006; 21 (Supl 1): p.40-44. 
30. Charon, R. O corpo que se conta: por que a medicina e as histórias precisam uma da outra. São Paulo: Letra e Voz, 2015.

\section{CONTRIBUIÇÃO DOS AUTORES}

Os autores participaram de todas as fases da elaboração deste manuscrito.

\section{CONFLITO DE INTERESSES}

Não contou com fonte de financiamento e não possui conflito de interesses.

\section{ENDEREÇO PARA CORRESPONDÊNCIA}

Carlos A. S. Garcia-Jr.

Universidade Federal de Santa Catarina/Campus Araranguá Rodovia Governador Jorge Lacerda, 3201. Sala 317.

Jardim das Avenidas

CEP 88906-072

Araranguá, Santa Catarina - Brasil

E-mail: carlosgarciajunior@hotmail.com 